\title{
GAMBARAN PENGETAHUAN REMAJA PUTRI TENTANG DISMINORE PADA MAHASISWA TINGKAT I PROGRAM STUDI DIPLOMA III KEPERAWATAN STIKES DIRGAHAYU SAMARINDA
}

\author{
Endang Wiwiek \\ Program Studi Diploma III Keperawatan STIKES Dirgahayu Samarinda \\ Jalan Pasundan No.21 Telp (0541) 748335, Fax. (0541)748335 \\ email: endangwiwiekpurnama@gmail.com
}

\begin{abstract}
ABSTRAK
Rasa nyeri saat haid merupakan keluhan ginekologi yang paling umum dan banyak dialami oleh wanita. Rasa nyeri saat haid tidak diketahui secara pasti kaitannya dengan penyebabnya, namun beberapa faktor dapat mempengaruhi yaitu ketidak seimbangan hormon dan faktor psikologis. Walaupun umumnya tidak berbahaya, namun sering kali dirasa mengganggu bagi wanita yang mengalaminya. Derajat nyeri dan kadar gangguan tentu tidak sama untuk setiap wanita. Ada yang masih bisa beraktifitas, ada pula yang tidak bisa beraktifitas karena nyeri. Dismenore ditandai dengan nyeri perut bagian bawah, mual, muntah, maupun gejala lainnya. Derajat nyeri tiap individu berbeda tergantung dari nyeri, persepsi, maupun pengalaman individu. Tujuan dari penelitian ini yaitu untuk memperoleh pengetahuan mahasiswi STIKES Dirgahayu Samarinda mengenai dismenore. Jenis penelitian ini adalah penelitian deskriptif. Teknik pengambilan sampel menggunakan teknik total sampling dari kriteria inklusi. Populasi dalam penelitian ini adalah mahasiswi tingkat I. Jumlah responden yang didapat yaitu sebanyak 50 responden. Metode yang dipakai dalam penelitian ini yaitu dengan menyebarkan kuesioner. Hasil penelitian ini menggambarkan bahwa tingkat pengetahuan termasuk dalam kategori baik 40 responden $(80 \%)$, mengetahui tanda dan gejala sebanyak 39 responden (78\%), penanganan dismenore sebanyak 32 responden $(64 \%)$.
\end{abstract}

Kata kunci : dismenore, tanda dan gejala, penanganan

\begin{abstract}
A sense of pain during menstruation is the most common and many gynecological complaints experienced by women. A sense of pain during menstruation is not known with certainty the relation to the cause, but several factors can influence namely hormonal imbalance and psychological factors. Although it is generally harmless, it is often felt annoying for women who experience it. The degree of pain and the level of the disorder are certainly not the same for every woman. Some are still able to do activities, some are not able to indulge in pain. Dysmenorrhea is characterized by lower abdominal pain, nausea, vomiting, and other symptoms. The degree of pain of each individual is different depending on pain, perception, and individual experience. The purpose of this study is to obtain an overview of the knowledge of STIKES Dirgahayu Samarinda students regarding dysmenorrhea. This type of research was descriptive research. Sampling technique used the total sampling technique from the inclusion criteria. The population in this study were first-level students. The number of respondents obtained was 50 respondents. The method used in this study is by distributing questionnaires. The results of this study illustrate that the level of knowledge included in the good category of 40 respondents $(80 \%)$, knowing signs and symptoms as many as 39 respondents (78\%), handling dysmenorrhea as many as 32 respondents $(64 \%)$.
\end{abstract}

Keywords: dysmenorrhea, signs and symptoms, treatment 


\section{PENDAHULUAN}

Rasa nyeri saat haid merupakan keluhan ginekologi yang paling umum dan banyak dialami oleh wanita. rasa nyeri saat haid tidak diketahui secara pasti kaitannya dengan penyebabnya, namun beberapa faktor dapat mempengaruhi yaitu ketidak seimbangan hormon dan faktor psikologis. Kesehatan reproduksi adalah suatu keadaan sejahtera fisik, mental dan sosial secara utuh, tidak sematamata bebas dari penyakit atau kecacatan dalam semua hal yang berkaitan dengan sistem reproduksi (Azwar, 2001).

Setiap bulan, secara periodik, seorang wanita normal akan mengalami peristiwa reproduksi, yaitu menstruasi meluruhnya jaringan endometrium karena tidak adanya telur matang yang dibuahi oleh sperma peristiwa itu begitu wajar dan alami sehingga dapat dipastikan bahwa semua wanita normal pasti akan mengalami proses itu. walaupun begitu kenyataannya banyak wanita yang mengalami masalah menstruasi, di antaranya adalah nyeri haid (Dismenore). Walaupun umumnya tidak berbahaya, namun sering kali dirasa mengganggu bagi wanita yang mengalaminya. Derajat nyeri dan kadar gangguan tentu tidak sama untuk setiap wanita. Dismenorea adalah kekakuan atau kekejangan di bagian bawah perut yang terjadi pada waktu menjelang atau selama menstruasi, yang memaksa wanita untuk beristirahat atau berakibat pada menurunnya kinerja dan kurangnya aktifitas sehari-hari. Ternyata di Indonesia, lebih banyak perempuan yang mengalami dismenorea tidak melaporkan atau berkunjung ke dokter. Rasa malu ke dokter dan kecenderungan meremehkan penyakit sering membuat data penderita tidak dapat dipastikan secara mutlak. Boleh dikatakan $90 \%$ perempuan pernah mengalami dismenore (Anurogo, 2011).
Berdasarkan latar belakang di atas dan menurut survey awal yang sudah dilakukan peneliti ternyata masih kurangnya pengetahuan remaja putri tentang dismenore, maka penulis tertarik melakukan penelitian mengenai tingkat pengetahuan remaja putri tentang tentang dismenore pada mahasiswi STIKES Dirgahayu Samarinda Program Studi Diploma III Keperawatan Tingkat I Tahun 2018

\section{METODE PENELITIAN}

Penelitian ini adalah penelitian deskriptif dimana peneliti menguraikan atau memberi gambaran atau deskripsi tentang suatu keadaan secara objektif mengenai pengetahuan mahasiswa tingkat I tentang dismenorea. Penelitian ini adalah penelitian deskriptif dimana peneliti menguraikan atau memberi gambaran atau deskripsi tentang suatu keadaan secara objektif mengenai pengetahuan mahasiswa tingkat I tentang dismenorea (Notoadmodjo. 2005). Rancangan dalam penelitian ini untuk mengetahui pengetahuan remaja putri tentang dismenore.

\section{Hasil Penelitian}

Tabel 5.1.1 Karakteristik Pengertian dismenore

\begin{tabular}{lclll} 
Responden & & & & \\
\hline Variabel & Frekue & Persen & Total & $\%$ \\
& & & & \\
\hline Tahu & 40 & 80 & 50 & 100 \\
Tidak tahu & 10 & 10 & & \\
& & & & \\
\hline
\end{tabular}

\section{Pada penelitian ini dari 50 responden mengetahui pengertian dismenore ada 40 orang (80\%).}

Tabel 5.1.2 Karakteristik Tanda dan gejala dismenore

\begin{tabular}{lcccc}
\multicolumn{2}{c}{ Responden } & & & \\
\hline Variabel & Frekuensi & $\%$ & Total & $\%$ \\
\hline $\begin{array}{l}\text { Tahu } \\
\text { Tidak }\end{array}$ & 39 & 78 & 50 & 100 \\
tahu & 11 & 22 & & \\
\hline
\end{tabular}


Berdasarkan hasil penelitian dari 50 responden 39 orang mengetahui tanda dan gejala. $(78 \%)$

Tabel 5.1.3 Karakteristik Penanganan dismenore

Responden

\begin{tabular}{lclll}
\hline Variabel & rekuensi & Persen & Total & Persen \\
\hline $\begin{array}{l}\text { Tahu } \\
\text { Tidak }\end{array}$ & 32 & 64 & 50 & 100 \\
tahu & 18 & 36 & & \\
\hline
\end{tabular}

Berdasarkan hasil penelitian dari 50 responden 32 orang (64\%) mengetahui cara penanganan dismenore

\section{Pembahasan}

\section{Pengetahuan remaja putri tentang pengertian dismenore}

Pengetahuan remaja putri tentang pengertian dismenore memiliki beberapa tingkatan yang salah satunya adalah tahu yang merupakan kemampuan mengenali atau mengingat materi yang telah didapat sebelumnya,sebagian besar responden sudah sesuai dengan teori Dari hasil penelitian didapatkan responden yang mengetahui tentang pengertian dismenore sebanyak 40 responden (80\%). Responden sebagian besar memiliki pengetahuan yang baik mengenai pengertian dismenore. Hal ini dapat disebabkan responden pernah mendapat materi tentang dismenore.

\section{Pengetahuan remaja putri tentang tanda dan gejala dismenore}

Tingkat pengetahuan tentang tanda dan gejala dismenore pada remaja putri dari hasil penelitian didapatkan 39 responden $(78 \%)$ responden mengetahui tentang tanda dan gejala, dan hanya 11 responden (22 $\%$ ) yang tidak tahu tanda dan gejala.Gejala dismenorea dapat disertai dengan rasa mual, muntah, diare dan kram perut. Menurut Winkjosatro
(2010), gejala dismenore adalah nyeri pada perut yang timbul sebelumnya, bersamaan dengan permulaan haid dan berlangsungbeberapa jam namun bisa sampai bertahan hingga beberapa hari.

\section{Sikap remaja putri tentang penanganan saat dismenorea.}

Tingkat pengetahuan tentang penanganan dismenore pada remaja putri dari hasil penelitian didapatkan 32 responden $(64 \%)$ responden mengetahui tentang penanganan, dan 18 responden (36\%) yang tidak tahu tentang penanganan dismenore. Pengetahuan responden tentang penanganan dismenorea dalam kategori cukiup. Arti cukup dapat diterjemahkan bahwa lebih dari 50\% responden mempunyai pengetahuan yang cukup sebelum melakukan penanganan dismenore.

\section{Kesimpulan}

Berdasarkan analisis data dan intepretasinya, maka dapat ditarik kesimpulan tingkat pengetahuan siswa tentang dismenore adalah sebagai berikut:

1. Tingkat pengetahuan remaja putri mahasiswi Program Studi Diploma III Keperawatan Tingkat I STIKES Dirgahayu Samarinda tentang pengertian dismenore dalam kategori baik sebanyak 40 orang $(80 \%)$.

2. Tingkat pengetahuan remaja putri mahasiswi Program Studi Diploma III Keperawatan Tingkat I STIKES Dirgahayu Samarinda tentang gejala dismenore dalam kategori cukup sebanyak 39 orang $(78 \%)$.

3. Tingkat pengetahuan remaja putri mahasiswi Program Studi Diploma III Keperawatan Tingkat I STIKES Dirgahayu Samarinda tentang penanganan dismenore dalam 
kategori cukup sebanyak 32 orang $(64,2 \%)$.

\section{Saran}

Berdasarkan kesimpulan hasil penelitian, maka disarankan sebagai berikut :

1. Bagi Perkembangan Ilmu Keperawatan :Hasil dari penelitian ini diharapkan dapat dijadikan sebagai sumber informasi dalam upaya pengembangan ilmu keperawatan khususnya dalam hal gambaran kejadian dismenore karena dismenore merupakan gangguan reproduksi. Perawat diharapkan agar dapat melakukan edukasi terkait upaya penanganan dismenore yang baik dan benar.

2. Bagi Institusi Tempat Penelitian

3. Hasil penelitian ini diharapkan dapat menjadi masukan bagi pihak kampus, untuk melakukan penanganan yang tepat agar dismenore yang dirasakan remaja putri tidak mengganggu aktivitas kuliah.

4. Bagi Peneliti Berikutnya

5. Hasil penelitian ini dapat menjadi informasi untuk peneliti selanjutnya yang melakukan penelitian terkait agar dapat mengembangkan variabel penelitian, sehingga dapat mengkaji hal-hal yang belum dimunculkan atau belum dibahas dalam penelitian.

\section{DAFTAR PUSTAKA}

Arikunto S. 2010. "Prosedur Penelitian Suatu Pendekatan Praktik. Jakarta : Rineka Cipta.

Anurogo, D. Wulandari, A. (2011). Cara Jitu Menangani Nyeri Haid.Yogyakarta: Andi Offset.

Azwar S. 2005. "Sikap Manusia, Teori Dan
Pengukurannya”.Yogyakarta;

Pustaka Pelajar. --2007. "Validitas dan Reliabilitas". Yogyakarta : Pustaka Pelajar.

Benson R. 2008. "Buku saku Obstetri dan Ginekologi”. Jakarta: EGC

Dewi, N. S. (2012). Biologi reproduksi. Yogyakarta: Pustaka Rihama

Defi Nafiroh, dkk, Gambaran Pengetahuan Remaja.tentang dismenore pada siswa putri di MTS NU Mranggen Kabupaten Demak. Jurnal Ilmiah Kebidanan, Vol. 4 No. 1 Edisi Desember 2013, hlm.157-166

Hiday at A. 2009. "Metode Penelitian Kebidanan dan Teknik Analisis Data Edisi2”. Jakarta: Salemba Medika

Jacoeb. 2006. "Dismenorea aspek patofisiologi dan pena talaksanaan”. Jakarta:

Kasdu D. 2005. "Solusi Problem Wanita Dewasa Cet. I". Jakarta : Puspa Swara.Kelly T. 2007.

Laila, N.N. 2011. Buku Pintar Menstruasi. Buku Biru: Yogyakarta

Lakhsmi, $\quad$ A. $\quad$ Saraswathi, P.Ramamchandran. 2011. Prevalence of Pre-Menstruasion Syndrome and Dysmenorrhoea among Female Medical Students and Its Associationwith College Absenteeism: International Jurnal of Biological \& Medical Research Vol 2(4): 1011 -1016

Llewellyn D. 2001. "Dasar-Dasar Obstetri dan Ginekologi”. Jakarta: Hipokrates 
Manuaba, Ida Bagus Gde, (2012).

Memahami KesehatanReproduksi

Wanita. Jakarta: Arean.

Morgan G. 2009. "Obstetri dan Ginekologi: Panduan Praktik”. Jakarta: EGC

Notoatmodjo S. 2010. "Metodologi Penelitian Kesehatan”. Jakarta : Rineka Cipta.

2012. "Promosi Kesehatan dan Perilaku”. Jakarta : Rineka Cipta.

Nursalam. 2008. "Konsep dan Penerapan Metodologi Penelitian Ilmu Keperawatan, . Jakarta : Salemba Medika.

Prawiroharjo, 2011. "Ilmu Kebidanan". Jakarta: Yayasan Bina Pustaka Sarwono Prawirohardjo

Proverawati,A. dan Misaroh, S. (2009).Menarche (MenstruasiPertama Penuh Makna). Yogyakarta:Muha Medika

Sarwono S. 2007. "Psikologi Remaja”. Jakarta : PT. Raja Grafindo Persada.

Saxena T, Kumari R, Khurana S, dan Rawat M. Effectivenes of dance therapy on primary dysmenorrhea in young females. Guru Drone Journal of Pharmacy \& Research. 2014; 2(3):11-16.
Soekanto S. 2004. "Sosiologi Keluarga Tentang Ikhwal Keluarga, Remaja, dan Anak”. Jakarta : Rineka Cipta.

Sugiyono. 2007. "Statistika Untuk Penelitian”. Bandung : Alfabeta.

Sukarni K, I \& Wahyu, P. (2013). Buku ajar keperawatan maternitas. Yogyakarta: Nuha Medika

Sulistina, D. 2009. "Hubungan antara Pengetahuan Menstruasi dengan Perilaku Kesehatan

Taufiqurrahman M. A. 2008. "Pengantar Metologi Penelitian untuk Ilmu Kesehatan”. Surakarta: LPP UNS

Tia M, Faktor-Faktor Yang Berhubungan Dengan Kejadian Dismenore Jurnal Kesmas Indonesia, Volume 8 No 1 , Januari 2016, Hal 40-48

Walgito B. 2003. "Psikologi Sosial (Suatu Pengantar)”. Yogjakarta: Andi Offset

Wiknjosastro H. 2009. "Ilmu Kandungan”. Jakarta: Yayasan Bina Pustaka Sarwono Prawirohardjo.

Yatim F. 2001. "Haid Tidak Wajar dan MenopauseEd. 1'. Jakarta : Pustaka Populer Obor. 